\title{
Análise fenomenológica da distração infantil
}

\author{
Daniela Ceron-Litvoc ${ }^{1}$
}

\section{Resumo}

Através da observação fenomenológica, esse artigo propõe a formulação de dois casos típicos ideais: o distraído-dissolvido e o distraído-absorvido. Ambos casos típicos descrevem crianças que teriam como apresentação clínica comum o sintoma desatenção (distração); porém, pelo método fenomenológico, é possível caracterizar as particularidades estruturais de cada caso. Enquanto o distraído-dissolvido apresenta uma estrutura de consciência desconectada do fluxo temporal contínuo, o distraído-absorvido apresenta uma estrutura de consciência distanciada do espaço externo com predomínio do interno. Ambas descrições receberiam o mesmo diagnóstico e a mesma proposta terapêutica de acordo com a classificação nosográfica por sintomas, porém, ao observar as diferenças estruturais, sugerimos intervenções distintas em cada caso.

Palavras-chave: Psicopatologia da Infância; Desatenção; Distração; DistraídoDissolvido; Distraído-Absorvido.

\section{Phenomenological analysis of child distraction}

\begin{abstract}
This article develops a theoretical formulation of two typical cases of distraction: the dissolved and the absorbed. Both descriptions can be grouped in symptom-based nomenclature as attentional deficit disorder, however the recognition of psychopathological manifestations allow the possibility of identification of distinct structures of conscience accordingly to the phenomeno-

\footnotetext{
${ }^{1}$ Psiquiatra coordenadora do "Ambulatório de Consultoria Escolar" do Serviço de Psiquiatria da Infância e Adolescência do Instituto de Psiquiatria da Faculdade de Medicina da Universidade de São Paulo. Psiquiatra pesquisadora do serviço de Psiquiatria da Infância e Adolescência do Programa de Atendimento e Pesquisa (PROVE) da Universiade Federal de São Paulo. Mestre em Psiquiatria pela Universidade Federal de São Paulo. Psiquiatra pelo Instituto de Psiquiatria da Faculdade de Medicina da Universidade de São Paulo. Membro fundador da Sociedade Brasileira de Psicopatologia Fenômeno-Estrutural. Email: daniela@ceronlitvoc.com
} 
structural approach. While in the dissolved-distracted structured the consciousness is disconnected from a continuous time flow, the absorbeddistracted has his structure spatially apart from the external inferences, prevailing the internal inferences. If identified as pertaining to the same group, as in mainstream nosological classification, the therapeutical interventions could be the same in both case descriptions. The Phenomenological method allows the identification of each structure beyond the symptoms, opening the view for discussion of structured-based interventions.

Key words: Child Psychopathology; Attention Distraction; DissolvedDistracted; Absorbed-Distracted.

\section{Introdução}

A forma de pensamento da psiquiatria atual, focada no reconhecimento de sinais e sintomas rigidamente estabelecidos para a denominação de quadros clínicos, impede um olhar que permita diferenciar as possibilidades de manifestações dos fenômenos psíquicos e ao core central, ou poderíamos chamar, a estrutura psíquica que os origina. A Fenomenologia, mais especificamente a Fenomenologia Estrutural, procura reconhecer exatamente as particularidades da manifestação de cada estrutura através dos fenômenos.

Essa abordagem é rica por alguns fatores, mas o principal na prática clínica seria que, através do delineamento de estruturas, pode-se propor tratamento tanto clínicos quanto psicoterápicos mais adequados a manifestação psicopatológica apresentada. A desvantagem é a dificuldade de generalização dos achados para condutas padrão.

As possibilidades de alterações de atenção na criança serão descritas nesse artigo na tentativa de delinear casos ideais, ou típicos. Essa abordagem é teórica, ou seja, com a ressalva que casos ideais não condizem exatamente com o que se pretende encontrar na prática diária de atendimento, mas tem seu papel em apresentar a forma de observação dos fenômenos e de apurar o olhar do observador.

Antes, como introdução do tema, é importante definir melhor o termo deficit de atenção. A palavra desatenção transmite o conceito de uma deficiência, um não funcionamento adequado da atividade de cognição atenção. Porém, para esse artigo, usaremos o termo alterações ou distrações, tentando já 
de início, explorar as particularidades da modulação da atenção. Assim como o humor, que é pressuposto mais estável do que se apresenta em alguns pacientes, poderíamos pensar na função mais friável, qualitativamente diferente, mas não ausente ou deficitária da atenção.

\section{Atenção}

Para iniciar o tema, faremos a seguinte pergunta: Qual é o papel da atenção para estrutura psíquica?

A atenção promove a abertura estável do contato vital para com o mundo para que a intencionalidade do indivíduo possa se desenrolar. Por exemplo, caso eu deseje observar um movimento qualquer ao meu redor e percebê-lo, preciso de uma condição de estabilidade psíquica para que esse fenômeno possa entrar em minha consciência. A atenção promove a claridade da consciência para o externo. É por ela que podemos criar o espaço interno para uma significação de mundo consciente, a elaboração do mundo. Tudo o que é abordado pela atenção torna-se presente dentro da consciência, presente em que se desenrola o desenvolvimento histórico.

A segunda pergunta a partir dessa premissa: Como seriam as possibilidades de distração?

Vamos delinear duas possibilidades estruturais diferentes que cursam com o mesmo sintoma: a distração. Usaremos a terminologia criada por Théodule Ribot (citado por Strauss, 1982): o distraído-dissolvido e o distraídoabsorvido, mostrando que apesar de um final comum, procedem de estruturas diferentes e que uma observação atenta pode perceber as nuances de cada uma.

\section{O distraído-dissolvido:}

Esse exemplo é a descrição comum das crianças tidas como desatentas. É a criança que se perde em pensamentos durante a explicação do professor e, posteriormente, não consegue resgatar onde sua mente estava. "No mundo da lua", tão inatingível quanto a metáfora sugere. É aquela criança tida como surda, ou melhor, intencionalmente surda pelos seus familiares, pois não escuta a maioria das coisas que se passam ao seu redor. Eventualmente, quando algo lhe é muito do interesse particular, ela escutaria. 
Quando perguntamos à criança o que acontece e quando temos sorte de que ela esteja conectada à pergunta o suficiente para olhar dentro de si mesma e observar-se (o que é uma tarefa difícil para uma consciência dissipada como veremos a seguir), encontramos respostas ocas e vazia. Para essa criança, os pensamentos vagam sem controle ou finalidade, sem foco, sem intencionalidade. A criança não está presente em sua divagação, pois ela não toma consciência dos acontecimentos externos ou internos. Na maior parte do tempo, ela é determinada pelo meio, ou seja, divaga sem controle a partir de estímulos externos.

O termo dissipado mostra a falta de intencionalidade, mesmo que momentânea, dessa consciência, em que, subitamente e sem controle, perde a possibilidade de existir como uma consciência autônoma no meio. Um som, um sopro ou um nada que lhe chame a atenção pode provocar a dissolução da sua consciência nos estímulos sensoriais. Existe uma aleatoriedade explícita, determinada pelo ambiente (não pela criança) e uma dissipação da estrutura da consciência do indivíduo, formando um todo ao mesmo tempo sintônico (aberto ao meio), porém sem resistência interna para a modulação dos estímulos de acordo com a volição individual.

As aferências externas poderão tornar-se tão imperiosas, abundantes e erráticaque podem construir uma realidade fragmentada a ponto impactar a formação da consciência individual coesa em contraposição ao meio. Assim não existe uma ressonância entre dois corpos (interno e externo), mas uma determinação do externo sobre uma consciência que não assume forma. Um exemplo é a entrada de líquido em uma área com formas delimitadas em que a nova substância preenche e promove características para o novo espaço, mas dentro das possibilidades de forma que lhe foram dadas, ou a entrada de líquido em um lugar sem forma; este irá apenas se esparramar e se perder, deixando rastro quase nenhum da sua presença. Essa é a consciência da criança realmente distraída.

Durante seu devaneio distraído, dissolvido no meio, ela não está presente porque ela não é capaz, neste momento, de vivenciar o presente; sua consciência está em suspenso desconectada do fluxo temporal. Se for chamada à realidade, ela subitamente retornará de seu devaneio sem conteúdo e sem personalidade, do devaneio a-histórico e a-pessoal, exatamente no mesmo ponto histórico \temporal de onde saiu quando sua mente se dissipou. Por isso, a resposta vazia que geralmente obtemos ao questioná-las.

Quando, ao atender uma criança com essa queixa, conversamos sobre como elas perdem objetos, por exemplo, a descrição que obtemos é que o que 
quer que esteja em sua mão em um momento, no seguinte é desaparecido. Não existe uma história mental, em cenas ou pensamentos.

Como exemplo, poderíamos contar a história de uma criança que perdeu um brinquedo favorito: ela estava brincando com o brinquedo, quando trouxeram um sanduíche. Deixou o brinquedo de lado para comer o sanduíche (novo objeto de interesse). Foi chamada para brincar com outros (novo objeto) e deixou o brinquedo lá pois não o tinha mais em sua consciência. Essa seria uma história comum na vida das crianças. Mas o distraído não conseguirá remontála, porque ele não consegue remontar a linha temporal dos fatos. As lembranças estão em sua mente, mas desconectadas, com lapsos temporais. O que aconteceu para que o brinquedo, que estava em suas mãos, teria desaparecido? Por mais que ele tente, ele não terá essa resposta. Ao ser submetido ao estímulo novo (o sanduíche), por alguns instantes, sua consciência foi suspensa pela magia do estímulo; onde estavam os outros fatos, onde a criança estava nesse período, não é possível de se responder.

Seria toda essa alteração desencadeada apenas pela ausência de uma função isolada, a atenção? Antes de responder essa questão, descreveremos a segunda estrutura possível para um distraído, o distraído-absolvido. A comparação de diferenças e semelhanças nos ajudará a avaliar as estruturas.

\section{O distraído-absorvido}

A criança distraída-absorvida, assim como a primeira, está longe da explicação do professor na sala de aula, mas quando chamada para retornar à realidade, ela poderá nos contar, não o que perdeu dos estímulos ao seu redor, mas sim onde estava. Ao contrário da primeira, não se encontra em um tempo a-histórico e sem fluxo individual, mas sim em seu tempo subjetivo com os seus devaneios. Enquanto a primeira é invadida pelo externo, a segunda está fechada ao externo. O seu pensar está focado em questões que são para ela essenciais. Ela não está sem presente (subjetivo) como o primeiro, ao contrário, está se desenvolvendo aderida à sua linha temporal, em que o pensar (mesmo em eventos do passado) acontece no presente, no tempo objetivo que pertence à realidade. A experiência está relacionada à realidade, mas não determinada pela realidade externa (absorto em seus pensamentos). Quando retorna à realidade objetiva da atenção aos eventos externos, retornará, do ponto de vista temporal objetivo, ao ponto de onde partiu sua distração. Mas o tempo interno, do desenvolvimento histórico, nunca foi interrompido, as experiências estarão sedimentadas em sua consciência. Não foi um tempo em aberto. 
A intencionalidade e a possibilidade de construção de uma linha biográfica individual em um fluxo temporal estão preservadas. A abertura para o externo, a claridade promovida pela atenção para que a consciência absorva aquilo que se desenrola em seu meio está diminuída em relação à claridade para as aferências internas.

\section{Análise Comparativa}

Essa segunda descrição deixa clara a diferença entre as duas crianças. Apesar de ambas poderem ser classificadas como desatentas e, sob o ponto de vista da nomenclatura psiquiátrica vigente, formarem a mesma categoria, elas apresentam estruturas formais de consciência bastante distintas. Assim, percebe-se que um mesmo sintoma (a distração) pode conter em si muitas possibilidades de origem, em diferentes estruturas. Ou seja, ao se falar em uma criança distraída, pode-se falar de quadros tão divergentes como os descritos aqui e que essas diferenças serão cruciais no desenvolvimento de cada uma.

A criança que apresenta em suspensão a consciência, à mercê de um devaneio sem individualização da experiência, fará uma recorte da realidade em que os objetos se apresentarão fragmentados. A percepção da realidade, fragmentada, tenderá a ter uma característica muito particular. O mundo não é o mesmo que ele se apresenta aos olhos dos seus pares, mas ele é, para essa criança, o recorte daquilo que ela vê ou vivência. A possibilidade da construção de um todo é substituída pela formaçào de uma colcha de retalhos com pedaços mal entrelaçados entre si, ou seja, existem lacunas que diminuem a possbilidade de previsiblidade do encadeamento dos fatos. Dessa forma, por exemplo, ela pode ser surpreendida pela resistência de algo externo que sempre esteve lá, mas que nunca foi visto.

As possibilidades de formação da realidade ao longo do desenvolvimento, construindo por fim um todo codificado em significados estáveis e confiáveis, não poderão ser realizadas. Essa criança, diferente das com atrasos cognitivos, não é impedida de formar um pensamento abstrato com significações da realidade, porém a que recorte ela se refere? Apenas àquilo que foi, ou por sorte ou afetivamente, determinado, selecionado. Por exemplo, ao estudar para uma prova, a dimensão do risco que se corre na nota que se vai obter vem da percepção da proporção de conhecimento adquirido e conhecimento ofertado pelo professor. Porém a criança distraída pode ir para o teste confiante de que sabe tudo, mas ser surpreendida que o seu tudo é um recorte bastante pouco abrangente do todo real. 
Já a criança que devaneia, mas não perde a sua intencionalidade, fará um recorte da realidade de acordo com o seu prisma de avaliação, mas as possibilidades de fragmentação serão menores. Ela sabe que não esteve presente na aula, ela percebe que perdeu fatos e dados (não ignora sua existência como a primeira), sabe que, ao estudar para a mesma prova, deverá fazer um esforço proporcional ao que se absorveu na sua realidade particular durante a aula. Essa criança tenderá, assim como a primeira, a criar um recorte da realidade, mas aquilo que foi excluído pela ausência temporária existe na consciência ao menos como sombra do que foi perdido, a ausência como algo que existe, mas não esteve presente. No distraído-dissolvido, a ausência é total pois ocorre uma suspensão, mesmo que temporária, da existência no fluxo temporal.

A possibilidade de construção de uma linha biográfica em cada modelo será também diferente. Para o primeiro, o dissolvido, o tempo vivenciado será sempre algo caótico, sem um fluxo contínuo, mas em ondas abruptas e não esperadas. Podemos, para exemplificar, pensar no tempo necessário para desempenhar uma atividade. A escala temporal objetiva é linear e, ao longo do desenvolvimento, adquire-se a possibilidade de parear duas categorias distintas: tempo cronológico necessário e empenho empregado para o desenvolvimento de uma atividade, formando um dos embriões da percepção de tempo subjetivo na consciência, o tempo/desempenho. Para essa criança, o tempo/desempenho é uma categoria caótica, pois os momentos de não desempenho não existem para a consciência. A possibilidade de percepção de um fluxo contínuo de tempo cronológico independente da volição individual é diminuída. Uma metáfora para exemplificar seria se só existisse consciência da existência dos dias e que as noite, por não serem "vistas" pela consciência fossem apagadas da existência. Tudo aquilo que aconteceria no tempo não visto seria mais do que ignorado, mas absolutamente não observado e não registrado. A tendência final é uma síntese de significações de absolutismos, ou seja, ou o tempo existe de forma infinita ou ele transcorreu sem controle. A experiência de um fluxo contínuo temporal como linha de base para a estabilidade é abalada, vivenciada como algo instável.

Enquanto a segunda criança, a absorvida, nunca se despregou da sua linha de tempo, apenas sua consciência se recolheu da realidade externa. $\mathrm{O}$ fluxo temporal é vivenciado e existe a possibilidade de realizar uma análise sintética de desempenho, volição, rendimento e finalização. A criança distraídadissolvida terá uma habilidade de recorrer à sua história biográfica temporal deficitária em relação à distraída-absorvida, tendendo a recortes e conclusões de seqüência distorcidas e não compartilhadas. 
Essa possibilidade de desenvolver uma história biográfica com relações causais explícitas determina a construção de modelos estáveis de relação com o meio. Por exemplo, ao realizar um ato para uma pessoa, quem realiza espera uma resposta de acordo com o entendimento de quem é esta pessoa, qual é o ato, o que essa associação proporcionará. Essa evolução causal é aprendida ao longo do desenvolvimento pela sedimentação das experiências em uma linha temporal mantida. Primeiro na forma prática, sensório-motora, com assimilação do real e do pensamento dos outros, mas ainda sem síntese e, depois, com a possibilidade da formação do pensamento, a possibilidade de síntese.

Caso, estruturalmente, não exista a possibilidade de realizar esse aprendizado em uma linha temporal contínua como é o distraído-dissolvido, a previsibilidade possível do mundo estará prejudicada. Como exemplo, uma pessoa que descreva suas experiências interpessoais como instáveis, injustas e impossíveis de serem decifradas pode se referir ao fato de que a capacidade dela de intersecção entre as duas subjetividades encontra-se comprometida. Apesar de uma empatia e afetividade preservada, a aderência ao interpessoal pode apresentar-se errática e caótica pelo olhar fragmentado determinado pelas dissoluções da consciência.

Já o distraído-absorvido contará com um grau de relacionamentos íntimos delimitados pela sua capacidade de permitir que o externo preencha o seu mundo íntimo. Mais distantes, eles podem perder muitos dados, estarem ausentes, inatingíveis. Porém, na sua história biográfica, esses elementos estão presentes e, ao receberem conseqüências causais na linha temporal de seu distanciamento com a realidade, terão esse fato como uma possibilidade e não uma surpresa. Apenas a sua história biográfica, apesar de muito coesa internamente, pode ser de pouca possibilidade de compartilhamento com os outros. Cada vez que se recolheu em seu mundo particular, o distraídoabsorvido não experimentou aquilo que aconteceu para todos que estavam ao seu redor, tornando-o um ausente da história compartilhada com os seus pares.

\section{Aplicabilidade do método de observação fenomenológica}

Ambas as crianças descritas aqui receberiam o mesmo diagnóstico de acordo com a classificação por sintomas. As possibilidades de tratamentos proposto para ambas seriam parecidas, partindo da premissa que se trataria do mesmo quadro. Mas, o olhar atento, mostra que enquanto uma apresenta-se aberta ao meio externo a ponto de fragmentar-se a segunda está fechada em um interno coeso e pouco ressonante. 
A possibilidade de observação dessas duas estruturas distintas determina intervenções diferentes. Deveríamos nos perguntar se a mesma proposta medicamentosa, por exemplo, o metilfenidato, teria respostas positivas em ambas. Provavelmente, no dissolvido, a medicação poderia promover uma restrição da determinação pelo meio, diminuindo a abertura (atenção involuntária) e permitindo a intencionalidade (atenção voluntária). No absorvido, a mesma medicação poderia promover um excesso de estímulos: o interno presente de forma ativa na consciência, mas sem a possibilidade de apagar o externo pela suspensão da atenção. Talvez, nessa estrutura, a medicação promoveria mais desconforto e ansiedade e uma tendência a um afastamento ainda maior (externo com menos estímulos).

$\mathrm{Na}$ intervenção psicoterapêutica, as diferenças também são explícitas. Enquanto no dissolvido, o olhar se daria para a possibilidade de formação de uma consciência autônoma e unitária com uma linha temporal/biográfica coesa, no absorvido a meta seria modular as possibilidades de abertura ao meio e de intersecção entre o interno e externo.

\section{Conclusão}

Observar o fenômeno, no caso a distração, e, através das manifestações, tentar intuir a estrutura que o gera é a meta fenomenológica. Ao perceber a transformação geradora abre-se uma percepção mais ampla do funcionamento arquitetônico da psique e, a partir de então, pode-se direcionar as intervenções. Ao observar as alterações primárias e consequiências secundárias no desenvolvimento da personalidade, conseguimos desenhar uma possibilidade de intervenção terapêutica mais próxima das necessidades do indivíduo.

\section{Referências bibliográficas:}

Straus, E. (1982). Man, Time, and World. Two contributions to anthropological psychology. Duquesne University Press. 